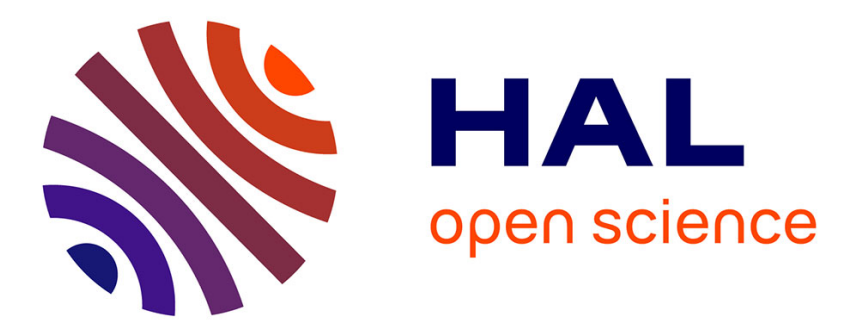

\title{
A.R.M. - Augmented Reality Muscularity
}

Dirk J.J. Sweere, Martin P. Hughes, Martijn G. van Laar, Lisa E. Rombout

\section{To cite this version:}

Dirk J.J. Sweere, Martin P. Hughes, Martijn G. van Laar, Lisa E. Rombout. A.R.M. - Augmented Reality Muscularity. 17th International Conference on Entertainment Computing (ICEC), Sep 2018, Poznan, Poland. pp.235-240, 10.1007/978-3-319-99426-0_23 . hal-02128593

\section{HAL Id: hal-02128593 \\ https://inria.hal.science/hal-02128593}

Submitted on 14 May 2019

HAL is a multi-disciplinary open access archive for the deposit and dissemination of scientific research documents, whether they are published or not. The documents may come from teaching and research institutions in France or abroad, or from public or private research centers.
L'archive ouverte pluridisciplinaire HAL, est destinée au dépôt et à la diffusion de documents scientifiques de niveau recherche, publiés ou non, émanant des établissements d'enseignement et de recherche français ou étrangers, des laboratoires publics ou privés.

\section{(c)(1)}

Distributed under a Creative Commons Attribution| 4.0 International License 


\title{
A.R.M. - Augmented Reality Muscularity
}

Dirk J.J. Sweere, Martin P. Hughes, Martijn G. van Laar, and Lisa E. Rombout $^{1}$

Tilburg University, Warandelaan 2, 5037 AB Tilburg, Netherlands, 1.e.rombout@uvt.nl

\begin{abstract}
The theory of embodied cognition states that cognition is influenced by the body we inhabit. Research on embodiment illusions has confirmed that our perceived body affects our behavior and disposition. Virtual and augmented reality applications make the experience of ownership over a different body more accessible, but these virtual bodies are seldom fully utilized. Instead, the focus often lies on the scenario or the virtual surroundings. As an initial exploration of the effectiveness of embodiment illusions within the domain of exergaming, we embodied participants with a virtual muscular arm. Results show that weight perception is not directly affected by this manipulation. However, we theorize that body alterations like this might affect players' motivation.
\end{abstract}

Keywords: augmented reality, virtual body, embodiment, experience design, exergaming, serious gaming, embodied cognition

\section{Introduction}

The field of embodied cognition encompasses several theories on how cognitive processes are rooted in the body [1]. Generally, it states that our mental constructs and task performance are influenced by the body we inhabit. Experience design in serious games is not commonly focused on the virtual body and its properties. Embodiment through virtual or augmented reality (VAR) might provide an additional psychological mechanism in creating effective gaming solutions.

\subsection{Experience design in exergaming}

Within serious games in general and exergaming in particular, the experience design often focuses on the narrative, the virtual surroundings, and the objects presented in the game. If a virtual body is present, it is often designed to either fit the task or to be a generic stand-in for the player. Merely the presence of a virtual body can already affect the player, for instance by reducing body-image anxiety [2], increasing the intention to engage in exergaming in the future [3], and heightening enjoyment of the game [4]. More enjoyable exergames can lead to longer periods of interaction, leading to positive health benefits [4].

However, altering the virtual body in specific ways could potentially lead to enhanced effectiveness of the experience. For example, differences in an avatars' 
body size affects motivation and physical activity $[5,6]$. Game performance can be improved by designing a body that is strongly associated with excellence on the task in the game $[7,8]$. Within exergames, one area strongly associated with stereotypical body-types is weight-lifting. Weight perception has been shown to be at least partly a top-down process [9]. For example, a dumbbell that has a bright color overlay induces less fatigue than a dark color [10]. Therefore, embodying a muscular virtual body could potentially also affect weight perception.

\subsection{Embodiment illusions}

Embodiment can be defined as 'the ensemble of sensations that arise in conjunction with being inside of, having, and controlling a body' [11]. The rubber hand illusion [12] shows that our sensation of embodiment is flexible and that we can feel embodied in artificial body parts, even if their location is slightly off. The illusion can be similarly evoked using VAR techniques [13], and show that multi-sensory input can override explicit knowledge of the body-image [14-16].

VAR technologies hold enormous potential in the domain of serious games, because of the tendency users have of treating the VAR environment as real, described as 'presence'. Presence correlates positively with task performance in virtual environments [17]. Induced embodiment is related to presence and can be an important contributor to the effectiveness of VAR experiences $[18,19]$.

However, the effects of embodiment illusions go further than that. Several studies show that behavioral tendencies — both in-game [7] and afterwards [20] - can be altered by placing the user in a certain type of body, making use of implicit associations the user has with that body-type. Similarly, these illusions can affect implicit biases [21] and attitudes [22]. Embodiment illusions thus allow us to alter a VAR experience in several meaningful ways.

The current study was designed to take a first look at the effects of an embodiment illusion with a muscular virtual arm through augmented reality. An AR application, rather than a VR one, has the potential to only change the elements of interest, and could safely be used in a gym during a real exercise [23]. We hypothesized that embodiment with a muscular arm would affect participants' weight perception in such a way that objects seem to weight less.

\section{Pilot study}

A small scale pilot study was conducted to test the setup and the virtual arm. 10 participants ( 7 female, 3 male) were randomly divided in a control group $(\mathrm{n}=5)$ and an experimental group $(\mathrm{n}=5)$. The participants' right arm was blocked from direct view. The control group saw their real arm on a screen, whereas the experimental group saw an overlay of a virtual arm. This 3D poly-model was created with the program MakeHuman and Blender 3D modeling software. It was attached to a marker using the Vuforia plug-in for Unity. Participants were instructed to close their eyes before a 150 gram apple was placed in the palm of their hand. For the experimental group, the virtual overlay changed to include a 
virtual apple. Both groups then looked at the screen and estimated the apples' weight. The experimental group lastly answered 3 embodiment questions, one on perceived strength, and one on naturalness, on a 7-point Likert scale [17].

The mean estimated weight of the apple was 200 grams $(\mathrm{SD}=61.24)$ in the control group, and 129 grams $(\mathrm{SD}=83.40)$ in the experimental group. Based on the questionnaire, the embodiment $(\mathrm{M}=3.6, \mathrm{SD}=1.67)$ and naturalness $(\mathrm{M}=3.8, \mathrm{SD}=1.1)$ seem to be comparable with the literature, but there was a lower score on perceived strength $(\mathrm{M}=2.2, \mathrm{SD}=.84)$. This might indicate that any effects are likely to be subconscious. The participants generally found it difficult to estimate the weight of the apple, reporting that they mainly used their knowledge of the weight of apples to make their guess. We concluded therefore that, although the virtual arm was sufficient to induce embodiment, the object to be weighted needed to be unknown to the participants.

\section{Methods Main Study}

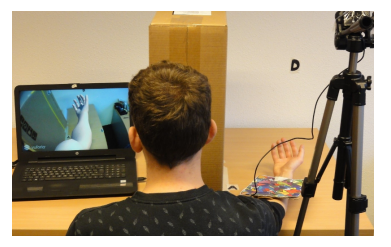

30 undergraduate students (17 female, 13 male), recruited at Tilburg University, were randomly divided in a control group $(\mathrm{n}=15)$ and an experimental group $(\mathrm{n}=15)$.

Participants were seated in front of the full screen application running on a computer screen, with their right arm on the other side of a barrier. For the exper-

Fig. 1. The AR condition imental group, the marker was attached to their lower arm using a stretch band. No changes were made to the model of the virtual arm. The camera was positioned just above the right shoulder (see figure 1).

Participants made a few movements with their arm (side-to-side and up and down), and were then asked to close their eyes. A glass paperweight (309 grams) was placed in the participants hand. A second video camera filmed their arm from the side to measure the arm drop, as a measurement of unconscious weight estimation. With their eyes still closed, participants were asked to estimate the weight of the object and for how long they believed they could hold it (added as a potentially more intuitive weight estimation). Afterwards the circumference of their arm was measured directly below the elbow, to control for how much the virtual arm diverged from their real arm. Lastly, the participants in the experimental group were asked to complete an extended embodiment questionnaire (8 items, 7 point Likert scale) [12].

\section{Results}

A Shapiro-Wilk test showed that for both conditions the estimated holding time did not follow a normal distribution (Control: $\mathrm{M}=8.87, \mathrm{SD}=8.06$, Virtual Arm: $\mathrm{M}=10.93, \mathrm{SD}=15.62$ ). Therefore the non-parametric Mann-Whitney test for independent samples was used, showing no significant difference between conditions $(\mathrm{p}=.85)$. 
The arm drop was measured from video by two independent observers. 2 participants were excluded due to their hand touching the desk during the drop. Both arm drop $(\mathrm{C}: \mathrm{M}=2.95, \mathrm{SD}=.88, \mathrm{VA}: \mathrm{M}=2.68, \mathrm{SD}=1.09)$ and weight estimation (C: $\mathrm{M}=873.33, \mathrm{SD}=686.83, \mathrm{VA}: \mathrm{M}=530.00, \mathrm{SD}=301.66)$ had a normal distribution. An independent samples t-test showed no significant differences of weight estimation $(\mathrm{p}=.09)$ and arm drop $(\mathrm{p}>.1)$ between conditions.

An ANOVA for estimated holding time with condition and gender as betweensubjects factors when controlling for arm circumference showed no significant main effects for both condition and gender. However, a significant disordinal interaction effect between condition and gender on estimated holding time was found $\left(\mathrm{F}(1,25)=7.52, \mathrm{p}=.01, \eta^{2}=.23\right)$. Analysis of variance showed no significant effect of condition and gender on both weight estimation and arm drop when controlling for arm circumference.

There was a significant correlation between arm drop and holding time $(\mathrm{r}(28)$ $=.44, \mathrm{p}=.02)$. The three weight estimation measurements and the embodiment questionnaire score $(\mathrm{M}=38.33, \mathrm{SD}=4.67)$ were not correlated.

\section{Discussion}

There were no significant differences between the two conditions for any of the weight perception measurements, and for the augmented condition none of the weight perception measurements were correlated with the embodiment questionnaire scores. Embodiment with a muscular virtual arm does not seem to influence participants' perceived or actual ability to hold and lift objects, and does therefore probably not influence weight estimation.

The interaction effect of condition and gender on estimated holding time could suggest that the virtual muscular arm was experienced as more compatible with male body-types, resulting in higher embodiment for men. However, a direct comparison of mean embodiment scores showed no significant difference. Alternatively, the extremely muscular arm could have induced stereotype threat. This type of priming can cause gender conforming behavior [24,25].

Since the arm drop is a physical reaction, unaffected by verbal cognition and knowledge about objects, its correlation with reported maximum holding time might indicate that an indirect estimation of weight is a more accurate measure for weight perception than a direct estimate.

A few limitations of this study have to be considered. Handedness of the participants was not recorded. All experiments were done using the right arm, so the sense of embodiment of left-handed participants may have been impacted. Additionally, measurements of the biceps might have been more informative than lower-arm circumference, since that muscle is used for lifting the forearm.

Although this study did not find a difference in weight perception using a virtual muscular arm, similar embodiment illusions might have different effects. VAR exercising applications have been shown to mainly affect enjoyment, motivation, and attitude [26,27], while psychological advantages are also enhanced by exercising in VR [28]. Exergaming is rated as more enjoyable and effective if 
the game focuses on entertainment [29]. Therefore, it is possible that the main effects of embodiment are also more attitude-based. Future studies could therefore focus more on the effects of embodiment illusions on motivation and enjoyment.

Embodiment illusions provide other interesting possibilities within exergames. For example, the virtual body could be used as a more intuitive feedback provider, where the body changes shape if the user engages with the experience. Feedback positively influences adherence to exercise [26], but is usually provided abstractly in the virtual environment instead of on the virtual body. Furthermore, the virtual body could be personalized in such a way that it provides the individual user with the benefits they need most. Entertainment technologies such as virtual and augmented reality hold the potential for the creation of personalized experiences, and the virtual body is an integral part of that.

\section{References}

1. Wilson, M.: Six views of embodied cognition. Psychonomic bulletin \& review $\mathbf{9}(4)$ (2002) 625-636

2. Song, H., Kim, J., Lee, K.M.: Virtual vs. real body in exergames: Reducing social physique anxiety in exercise experiences. Computers in Human Behavior 36 (2014) $282-285$

3. Kim, S.Y.S., Prestopnik, N., Biocca, F.A.: Body in the interactive game: How interface embodiment affects physical activity and health behavior change. Computers in Human Behavior 36 (2014) 376-384

4. Mellecker, R., Lyons, E.J., Baranowski, T.: Disentangling fun and enjoyment in exergames using an expanded design, play, experience framework: A narrative review. GAMES FOR HEALTH: Research, Development, and Clinical Applications 2(3) (2013) 142-149

5. Peña, J., Khan, S., Alexopoulos, C.: I am what i see: How avatar and opponent agent body size affects physical activity among men playing exergames. Journal of Computer-Mediated Communication 21(3) (2016) 195-209

6. Li, B.J., Lwin, M.O., Jung, Y.: Wii, myself, and size: The influence of proteus effect and stereotype threat on overweight children's exercise motivation and behavior in exergames. GAMES FOR HEALTH: Research, Development, and Clinical Applications 3(1) (2014) 40-48

7. Kilteni, K., Bergstrom, I., Slater, M.: Drumming in immersive virtual reality: the body shapes the way we play. IEEE transactions on visualization and computer graphics 19(4) (2013) 597-605

8. Osimo, S.A., Pizarro, R., Spanlang, B., Slater, M.: Conversations between self and self as sigmund freuda virtual body ownership paradigm for self counselling. Scientific reports 5 (2015) 13899

9. Ellis, R.R., Lederman, S.J.: The golf-ball illusion: Evidence for top-down processing in weight perception. Perception 27(2) (1998) 193-201 PMID: 9709451.

10. Ban, Y., Narumi, T., Fujii, T., Sakurai, S., Imura, J., Tanikawa, T., Hirose, M.: Augmented endurance: Controlling fatigue while handling objects by affecting weight perception using augmented reality. In: Proceedings of the SIGCHI Conference on Human Factors in Computing Systems. CHI '13, New York, NY, USA, ACM (2013) 69-78 
11. Kilteni, K., Groten, R., Slater, M.: The sense of embodiment in virtual reality. Presence: Teleoperators and Virtual Environments 21(4) (2012) 373-387

12. Botvinick, M., Cohen, J.: Rubber hands feeltouch that eyes see. Nature 391(6669) (1998) 756

13. IJsselsteijn, W.A., de Kort, Y.A.W., Haans, A.: Is this my hand i see before me? the rubber hand illusion in reality, virtual reality, and mixed reality. Presence: Teleoperators and Virtual Environments 15(4) (2006) 455-464

14. Blanke, O., Metzinger, T.: Full-body illusions and minimal phenomenal selfhood. Trends in cognitive sciences 13(1) (2009) 7-13

15. Slater, M., Spanlang, B., Sanchez-Vives, M.V., Blanke, O.: First person experience of body transfer in virtual reality. PloS one 5(5) (2010) e10564

16. Lenggenhager, B., Tadi, T., Metzinger, T., Blanke, O.: Video ergo sum: manipulating bodily self-consciousness. Science 317(5841) (2007) 1096-1099

17. Schuemie, M.J., Van Der Straaten, P., Krijn, M., Van Der Mast, C.A.: Research on presence in virtual reality: A survey. CyberPsychology \& Behavior 4(2) (2001) 183-201

18. Biocca, F.: The cyborg's dilemma: Progressive embodiment in virtual environments. Journal of computer-mediated communication 3(2) (1997) JCMC324

19. Tamborini, R., Skalski, P.: The role of presence in the experience of electronic games. Playing video games: Motives, responses, and consequences (2006) 225240

20. Rosenberg, R.S., Baughman, S.L., Bailenson, J.N.: Virtual superheroes: Using superpowers in virtual reality to encourage prosocial behavior. PloS one $8(1)$ (2013) e55003

21. Peck, T.C., Seinfeld, S., Aglioti, S.M., Slater, M.: Putting yourself in the skin of a black avatar reduces implicit racial bias. Consciousness and cognition 22(3) (2013) 779-787

22. Banakou, D., Groten, R., Slater, M.: Illusory ownership of a virtual child body causes overestimation of object sizes and implicit attitude changes. Proceedings of the National Academy of Sciences 110(31) (2013) 12846-12851

23. Riva, G., Baños, R.M., Botella, C., Mantovani, F., Gaggioli, A.: Transforming experience: the potential of augmented reality and virtual reality for enhancing personal and clinical change. Frontiers in psychiatry 7 (2016) 164

24. Spencer, S.J., Steele, C.M., Quinn, D.M.: Stereotype threat and women's math performance. Journal of experimental social psychology 35(1) (1999) 4-28

25. Nguyen, H.H.D., Ryan, A.M.: Does stereotype threat affect test performance of minorities and women? a meta-analysis of experimental evidence. Journal of applied psychology 93(6) (2008) 1314

26. Annesi, J.J.: Effects of computer feedback on adherence to exercise. Perceptual and Motor Skills 87(2) (1998) 723-730 PMID: 9842630.

27. Daniel, R., Ewald, M., Maiano, C.: Virtual reality and exercise: behavioral and psychological effects of visual feedback. Annual Review of Cybertherapy and Telemedicine 2011 (2011) 99

28. Plante, T.G., Aldridge, A., Su, D., Bogdan, R., Belo, M., Kahn, K.: Does virtual reality enhance the management of stress when paired with exercise? an exploratory study. International Journal of Stress Management 10(3) (2003) 203

29. Lyons, E.J., Tate, D.F., Komoski, S.E., Carr, P.M., Ward, D.S.: Novel approaches to obesity prevention: Effects of game enjoyment and game type on energy expenditure in active video games. Journal of Diabetes Science and Technology 6(4) (2012) 839-848 PMID: 22920810. 